\title{
Article
}

\section{Health social movements and the hybridisation of 'cause regimes': an ethnography of a British childbirth organisation}

Roberts, Celia, Tyler, Imogen, Satchwell, Candice and Armstrong, Jo Available at https://clok.uclan.ac.uk/12677/

Roberts, Celia, Tyler, Imogen, Satchwell, Candice orcid iconORCID: 0000-00018111-818X and Armstrong, Jo (2016) Health social movements and the hybridisation of 'cause regimes': an ethnography of a British childbirth organisation. Social Movement Studies, 15 (4). pp. 417-430. ISSN 1474-2837

It is advisable to refer to the publisher's version if you intend to cite from the work. /10.1080/14742837.2016.1149058

For more information about UCLan's research in this area go to http://www.uclan.ac.uk/researchgroups/ and search for <name of research Group>.

For information about Research generally at UCLan please go to http://www.uclan.ac.uk/research/

All outputs in CLoK are protected by Intellectual Property Rights law, including Copyright law. Copyright, IPR and Moral Rights for the works on this site are retained by the individual authors and/or other copyright owners. Terms and conditions for use of this material are defined in the policies page. 


\title{
Health Social Movements and the Hybridisation of 'Cause Regimes': \\ An Ethnography of a British Childbirth Organisation \\ Celia Roberts, Imogen Tyler, Candice Satchwell and Jo Armstrong
}

\author{
Affiliations \\ Celia Roberts, Imogen Tyler and Jo Armstrong: Department of Sociology, Lancaster \\ University, Lancaster \\ Candice Satchwell, Education and Social Science, University of Central Lancashire, Preston
}

\begin{abstract}
This article reports on an ethnographic study of the UK's largest health advocacy organisation dedicated to pregnancy, childbirth and parenting, the National Childbirth Trust or NCT. Working from interview data, textual materials and fieldnotes, we articulate three key phases in the NCT's historically shifting relationships to feminism, medicine, the state and neoliberal capitalism. The concept of folded cause regimes is introduced as we examine how these phases represent the hybridisation of the organisation's original cause. We argue that for the NCT the resulting multiplicity of cause regimes poses significant challenges, but also future opportunities. The apparent contradictions between cause regimes offer important insights into contemporary debates in the sociology of health and illness and raises critical questions about the hybrid state of health advocacy today. Focussing on cause allows for a deeper understanding of the intense pressures of diversification, marketisation and the professionalization of dissent faced by third sector organisations under current social and economic conditions.
\end{abstract}


Key words: National Childbirth Trust, Health Social Movements, cause regimes, childbirth, feminism, third-sector, neoliberalism.

\section{The Changing 'Cause Regimes' of Health Social Movement Organisations}

Contemporary health social movement organisations (HSMOs) exercise notable political and social power. The sociological study of their activities and effects has developed as they have multiplied in number and governments have opened up policy processes to their influence (Landzelius 2006a, Epstein 2007; Baggott \& Forster 2008; Allsop et al 2004, Alvarez-Rosete \& Mays 2008) but there is little research into their historical development. ${ }^{i}$ In 2007 Steven Epstein suggested that historical analysis would contribute to understandings of health activism's capacity to affect policy, practice and individual experience; to alter what Maren Klawiter (2006) calls 'cultures of disease and activism'.

This article draws on the European Commission-funded project 'European Patient Organisations in Knowledge Society' (EPOKS). Investigating HSMOs across four national contexts (Ireland, the United Kingdom, France and Portugal) and condition areas (Alzheimer's Disease, Attention Deficit Hyperactivity Disorder, rare diseases and childbirth) EPOKS addressed the absence of work on the history of HSMOs. As our colleagues write: In the first phase..., which began in early 2009 , we traced the histories of a number of organisations.... Based primarily on documentary-archival analysis, we 
systematically tracked the organisations' historical trajectories along a number of dimensions (e.g. cause, constituency and web of relations). Using a common framework, for each organisation we sought to identify main historical turning points and characterise its public positionings. Questions posed included when and why was the organisation established? As what kind of organisation has it self-identified (e.g. self-help, advocacy or 'war on disease')? What are the main changes it has sought to bring about? Who are its allies (and opponents)? (O'Donovan et al 2013: $3)$.

During early attempts to formulate a common framework, Michel Callon suggested focussing on the 'organisational cause/s' forming and motivating HSMOs' activities over time. This focus proved invaluable in the second research phase. Analysing the forms of knowledge produced and circulated by HSMOs, we explored the 'public enunciations of the missions around which they mobilised,' asking 'for what is the organisation fighting, what kind of fight is this and on whose behalf is it being fought?' (O'Donovan et al, 2013: 5).

Building on Klawiter (2004)'s term 'disease regimes', EPOKS colleagues developed the concept of 'cause regimes' to theorise the periodization of Alzheimer's Disease (AD) HSMOs: By cause regime, we refer to who and what a health movement organisation is fighting for, as articulated in its public self-identifications. In addition, it refers to the broader framing of the cause, for example, as a political or charitable one. Lastly, the concept underscores how organisations' public self-identifications of their cause can govern or regulate their operation, including their interactions with and representations of those on whose behalf they advocate (O'Donovan et al, 2013: 2). 
In their work on AD organisations, O'Donovan et al identify a significant shift from cause regimes focussing on carers to ones oriented towards those living with $A D$ and their carers. Their analysis of historical shifts in AD cause regimes highlights the ways in which 'cause hybridisation' (associated with HSMOs' increase in size and impact) can undermine its and its members' vision of 'original' motivating cause and 'give rise to a series of organisational tensions and challenges' (O'Donovan et al, 2013: 2). Arguably, O'Donovan et al's work focusses rather more on 'cause' than on 'regime.' As in Klawiter's study of historical shifts in American breast cancer activism, the term 'regime' refers to the ways in which institutional and organisational practices congeal and dissolve over time. Regimes are inherently connected to causes in this line of thinking: practices of activism, collective mobilisations and the motivations for these are always in process. The very definitions of a health condition and those who suffer from it are made in part through HSMO's changing cause regimes.

In this paper we analyse the work of the birth and parenting advocacy organisation, the National Childbirth Trust or NCT. ii Detailing the shifting nature of its public enunciations of its cause, we explore the significance of the practices constituting its activism regimes. We argue that the NCT's cause regime has shifted enormously over the last 50 years with a notable trend away from confrontational politics towards collaboration with state and corporate actors. Indeed, the very understanding of 'cause' as a set of foundational principles to struggle for has, at least in some highly visible parts of the NCT, been rejected and reconfigured into forms of contractual collaboration and market opportunity. Such changes are part of neoliberal agendas, as has been argued in other cases (see Tyler et. al. 2014) but importantly are not absolute: we argue here that historic cause regimes are 
'folded' rather than supplanted over time. Borrowed from Michel Serres (1995: 60), the term 'folded' rejects the conventional view describing historical periods as sequential, arguing that time is best conceived as topological rather than geometric and thus that objects, ideas or events that are temporally distant in their origin can exist in close physical proximity, together constituting something 'contemporary'. Like objects or ideas, we suggest, 'cause regimes' are disparate aggregates, blending or folding older causes with newer ones.

In social movement studies, the concept of framing has been developed to analyse the ways in which opportunities for collective action emerge in specific geopolitical and historical time-frames. Hank Johnston and John Noakes' (2005) Frames of Protest: Social Movements and the Framing Perspective, employs framing to theorise the rise and fall of social movements, focussing on how movements 'reframe' themselves in order to organise, rally and utilize political and resource opportunities at particular moments. We extend this approach through developing the conceptual device of 'cause regimes'. Cause regimes allow us to track how organisational motivations and strategies are not only reframed (through specific campaigns for instance) but multiply over time in ways that allow for the coexistence of incompatible ideologies and practices within an organisation. In the NCT whilst older cause regimes are overlaid by newer ones, elements of older regimes bubble along under the radar and/or in specific pockets of practice. In an organisation as old and large as the NCT, conflicting cause regimes co-exist. Whilst this creates tensions, these do not seem to be fatal and indeed may help secure the longer term survival of a HSMO. Tracing folded cause regimes helps us to understand how the powerful neoliberal co-option and 
repurposing of HSMOs might be resisted through the reactivation of other enduring activist causes.

\section{Studying the NCT}

This article draws on an ethnography conducted in 2010-2012. Data collection involved reading printed and web resources; undertaking ten formal interviews with leading NCT figures (including the CEO, Chair and Research Director), 'ordinary' members and service users (recruited locally through snowball sampling); observing (and sometimes actively participating in) national and local meetings and conferences, member training sessions, ante-natal classes and fundraising events. ${ }^{\text {iii }}$ In the analysis phase, data extracts and arising themes were discussed in local and international project team meetings, allowing us to both compare birth politics across four national settings and in one pan-European organisation and to contrast birth politics with health activism in the three other fields covered in EPOKS. We also shared preliminary analyses with NCT members and other HSMOs, both informally and in a two-day participative workshop held in 2011. iv

Established over 50 years ago, the NCT is the largest UK HSMO dedicated to pregnancy, childbirth and parenting. Its size and longevity makes it an interesting and surprisingly under-researched case (a chapter by Jenny Kitzinger is the only existing in-depth sociological analysis). Although, like other HSMOs (e.g. Layne 2006; Akrich, 2010) the NCT overflows simple classification, our textual, interview and observational data lead us to identify three key cause regimes in its history. During the first phase (mid 1950s-1970s), the common organisational cause was primarily framed as 'natural childbirth'; the NCT's mission was to 
educate women. This period was underpinned by eugenicist, post-imperial ideologies. Lobbying and pedagogical practices took place at both national and local scales, focussing almost exclusively on childbirth. In the second phase (1970s-2000), lobbying and education continued but the NCT framed their cause as championing the rights of women to make choices about childbirth. Shaped by liberal feminist ideals and critical consumerism, this was a time of substantial development in the organisation's policy influence. The current regime (2000-present) - arguably the most dramatic change in organisational cause - entails a shift towards more generic 'parenting skills education', government service provision and the marketisation of the NCT as a brand. Today the NCT campaigns on issues as diverse as access to healthcare (e.g. choice of place of birth) and questions of embodied identity (e.g. having a 'natural' experience of birth) and claims to represent an amorphous constituency of 'parents'.

As in the AD organisations' case, the NCT's history highlights 'a hybridising shift in the organisations' cause regimes and a process of domain expansion' (O'Donovan et al, 2013: 5). This hybridity is apparent in current claims to multiple areas of expertise (including childbirth, infant-feeding and care and early years parenting) and practice (through expert evidence, policy formation, hospital and patient pressure groups, birth education and support and increasingly parenting training and commercial activities such as baby fairs and product endorsements). This expansion and hybridisation risks producing 'dysfunctional movement dynamics....and internal conflict' (O'Donovan et al, 2013: 5) and undermining the organisation's potential to effect change.

\section{The Big Weekend}


In May 2010 we attended the NCT's annual conference, 'The Big Weekend', as participant ethnographers: undertaking observations, taking photographs and contributing to a training session in scientific literacy. This was a chance to see NCT members en masse: although constituting just $1 \%$ of the NCT's membership, the 1000 -strong crowd and the activities organised by and for them embodied a diversity that we also encountered in interviews and textual and web analysis. Incorporating workshops, activities for children, stalls and inspirational talks by celebrities, the conference encapsulated both energy and excitement and the palpable tensions, contradictions and challenges which we theorise as symptomatic of the historical hybridisation of the NCT's 'cause regimes'. Ethnographic data from the Big Weekend structure this paper; our fieldnotes from three keynote speeches articulate historical cause regimes identified by our broader ethnography. As we will show, each speaker invoked a different time period: 1950s origins; engagement with 1970s feminist politics; and present day concerns with branding, consumers and markets. Exploring these three periods, we argue that as the NCT has grown and professionalised, it has developed multiple organisational 'cause regimes' that pull in politically contradictory directions.

\section{Fieldnote excerpt: Performing Origin Stories}

In a crowded plenary session in an enormous floodlit convention centre, outgoing NCT President Gail Werkmeister purposively walked on stage accompanied by John Lennon's 1971 political pop track 'Power to the people'. Werkmeister delivered a rousing speech invoking the NCT's long history, using PowerPoint slides to periodise the organisation: a photograph of the NCT's founder Prunella Briance, an image of the first members' conference in 1992 and, emphasising the organisation's political activism, a photograph of 
the 'Reclaiming Birth Rally' held in London in March 2010. After her talk Werkmeister introduced 80 year old Gwen Rankin, an NCT founding member. Rankin's appearance was greeted with a standing ovation and sustained applause... and Rankin spoke briefly about the inspiring growth of the organisation from its early days.

\section{INSERT FIGURE 1 HERE}

Figure 1: Gail Werkmeister and NCT founding member Gwen Rankin at the NCT Big Weekend, May 2010. Photograph, Imogen Tyler with permission.

Werkmeister's performance of the NCT's origin story at 'The Big Weekend' demonstrates the importance of the organisation's history to its current identity. The rapturous applause greeting Rankin indicates the kind of collective feeling these origin stories generate amongst members. Performing the organisation's history is rhetorically significant in establishing the NCT's position as a key actor in UK childbirth policy: in interviews senior NCT members repeatedly invoked the organisation's long history to explain its current position of power in policy-making circles. For the NCT, its history has become a cause in its own right. Speaking informally about a younger organisation's challenge to the NCT's authority in a particular policy debate, for example, a senior member said:

We are powerful and we have worked hard to be. I have worked for the NCT for 25 years. We've been going for 50 years - it didn't just happen. Our history is very important to us. (fieldnotes)

Despite what Jenny Kitzinger (1990:113) describes as 'a chequered history, involving a constant tension between challenge and compromise, radicalism and reform,' there 
remains a prescient sense of shared history and beliefs in the organisation. Origin stories published on the NCT website ${ }^{v}$ and in the book New Generations: 40 Years of Birth in Britain (Moorhead, 1996) produce a coherent account of the organisation's evolution. In contrast, our research suggests a more complex, hybrid and fractured history and the existence of multiple cause regimes. Following these lines of tension in the organisation is, we suggest, important for understanding its current status and its potential to influence maternity services and policies in the UK.

\section{Doctor Knows Best}

As it is usually told, the NCT began with events in 1956 when Prunella Briance, wife of a British Ambassador, sought advice from controversial British obstetrician Grantly Dick-Read (1890-1959). Briance had suffered a traumatic emergency Caesarean birth and, pregnant again, was seeking alternatives. Dick-Read's best-selling book, Childbirth Without Fear (1944) was inspired by his work in the deprived East End of London and in South Africa, where he had observed women giving birth with apparently little pain: Dick-Read believed that 'women of the more primitive types' had retained the art of 'natural childbirth' (Caton 1996: 955). In contrast, Dick-Read argued, fear had become a physiological obstacle to childbirth amongst leisured and educated middle- and upper-class women. He claimed that his methods would allow $96 \%$ of women to have painless labours, resulting in closer bonding with their babies.

Despite her efforts to employ these methods, Briance's second baby was born dead, an outcome she blamed on medical interventions. In May 1956 she placed an advertisement in the Times and the Daily Telegraph, announcing that 'A natural childbirth association is to be 
formed for the promotion and better understanding of the Dick-Read system.' Briance later stated 'I was astonished at how many women wanted to get in touch and lend their support. It showed how very great the need was to set up such an association' (cited in Moorhead 1996: 3). The Natural Childbirth Association of Great Britain was launched in 1957; a social event attended by women from Briance's influential social milieu. As Jenny Kitzinger (1990: 100) notes, 'the gentrification of natural childbirth' was a political strategy of the NCT that persisted well into the mid-1960s.

The period in which Dick-Read rose to prominence was one of intense post-imperial statebuilding and significant immigration from former British colonies. His vision of natural childbirth and 'the perfection of motherhood' (cited in Thomas, 1997: 14) emerged against the backdrop of the two world wars, the diminishing power of the British Empire and the emergence of a global atomic age. As Ornella Moscucci (2003: 169) argues, Dick-Read's theory of natural childbirth developed amidst wider eugenicist concerns about 'the differential birth rate-the tendency of poorer, less healthy sections of society to have larger families than their "betters".' One of the central 'causes' for the natural childbirth movement was encouraging elite, white British mothers to "reproduce the nation" in the face of imperial decline and the threat imagined to be posed by changing gender relations (Tyler, 2013; Davis, 2012).

Although particular obstetric interventions (such as analgesics) were eschewed in this model, pregnant and labouring women were enrolled in new forms of expert surveillance and instruction. Dick-Read's wife Jessica set up antenatal classes in London and members invited to become 'area organisers' were given copies of Dick-Read's long-playing vinyl 
record Natural Childbirth: A Documentary Recording of a Birth of a Baby delivered by Grantly Dick-Read (1957) to lend to pregnant women. The NCT regularly screened Childbirth Without Fear (1956), a 20 minute colour film depicting women giving birth in Dick-Read's Johannesburg clinic. In the 1960s, the NCT transferred its allegiance from Dick-Read to Lamaze's theory of 'prepared birth' (Kitzinger, 1990: 94-5). With this shift, Jenny Kitzinger (1990: 107) notes, the imagery in NCT publications 'changed to one of victory of the body rather than surrender to it.' However the NCT continued to train women to defer to medical professionals, aiming to help women by producing them as compliant, self-controlled maternity patients.

Origin stories are central to the NCT's identity and cause as a campaigning childbirth organisation, although the stories change as the organisation's relationship to medical authority and its complex relationship with feminism and sexual politics transforms. Tracking such shifts raises questions about the NCT's contemporary relation to medical expertise and the ways in which members variously challenge and ally themselves with medical professionals delivering maternity care.

\section{Fieldnote excerpt: Women's Knowledge - A Liberal Feminist Cause}

On the opening afternoon of The Big Weekend, three hundred women crowd into a lecture hall to hear US birth activist Ina May Gaskin. The audience are predominately white, some are pregnant and others are nursing babies. The atmosphere is electric as Gaskin comes onto the stage. Gaskin is one of the most influential midwives in the world, founding the Farm Midwifery Center in Tennessee in 1971 and engaging in global speaking tours. Her first book Spiritual Midwifery (1977) remains a best-selling classic of radical midwifery and homebirth. 
On stage Gaskin is framed by an image of 'The Safe Motherhood Quilt', each square of which depicts a woman who has died as a consequence of pregnancy and childbirth in the U.S in the last twenty years. Her speech is rousing and inspirational: she rails against US obstetrics, arguing that what are understood as advances in maternal care in fact endanger women's lives as obstetric medicine deskills itself with each passing generation in an assembly-line medical system whose agendas are driven by insurance and pharmaceutical companies and in which the lives of the unborn are prioritised over the lives of women. She criticises patriarchal medicine and talks about women getting back in touch with their bodies, about the lost knowledges of midwifery and 'witchcraft' we need to relearn and adapt. Gaskin's passion and moral fervour animates the audience. There is rapturous applause.

Gaskin's presence and the audience's jubilant response open up the question of the NCT's relationship to the Women's Health Movement of the 1970 s and 80 s. This period saw a notable rise in protest activities around women's health, including birth. Responding to the changing political climate, elements of the NCT shifted away from promoting particular obstetric perspectives, becoming more critical of the medicalization of birth. Jenny Kitzinger states:

It was the increasingly interventionist nature of obstetrics in the 1970s that had the most dramatic effect on the Trust's relationship with the medical profession. Organisational causes transform according to what an organisation is fighting and with the rise in obstetric interventions, particularly inductions, the NCT began publicly to challenge the golden rule of 'doctor knows best' (Kitzinger, 1990: 111). 
Childbirth-related activism flourished in the UK in the 1970s and organisations like the Association for Radical Midwives (1975) and Maternity Alliance (1977) emerged. Previously working with obstetricians and side-lining midwifery, the NCT now began to collaborate with organisations like the Association for Improvements in Maternity Service (AIMS). However, the NCT remained the conservative partner in its relationships with more feminist organisations, juggling patriarchal ideals inherited from its founding ideology with feminist revaluing of women's embodied knowledge.

The 1970s also saw the intensified medicalisation of birth in the UK. In 1970, after problems providing enough hospital beds for birthing women, the government's Peel Report stated: 'We consider that the resources of modern medicine should be available to all mothers and babies, and we think that sufficient facilities should be provided to allow for $100 \%$ hospital delivery' (Department of Health, 1970). This recommendation normalised a range of medical practices including inductions on the due date, foetal monitoring and women being required to give birth lying down. Alongside other organisations, the NCT worked to contest these practices through creating and circulating alternative knowledges about birth based both on collecting anecdotes and more scientifically aligned research practices.

One of the earliest NCT members was feminist activist and writer Sheila Kitzinger, who became an NCT antenatal teacher in the 1960s and claims to have introduced the tutorial system for training NCT teachers. A prolific writer on birth and breastfeeding, she produced several key pieces of research for the organisation in the 1970s and 80s. Trained in social anthropology, Kitzinger favoured qualitative methods focussing on women's emotional and physical experiences. In 1975, for example, she wrote the NCT's first research report 'Some 
Mothers' Experiences of Induced Labour' (Kitzinger, 1975) introducing women's voices into the childbirth policy arena for the first time.

In interview, Sheila Kitzinger described herself as "an irritation to them [the NCT]" because she challenged their "soft" approach. For her, the NCT was too closely aligned with DickRead:

Of course because the NCT started with adoration of Dick-Read and stayed that way in a rather static form for some time, there was also tension between those who were disciples of Dick-Read and others who wanted to forge ahead and look at other ways of approaching it and other systems of teaching and so on. (Interview, 2010)

Kitzinger also clashed directly with Dick-Read around research: she recalled a conversation with Jessica and Grantly Dick-Read:

I remember too, because I'm interested in research evidence, them staying with us because I'd organised a meeting in Oxford, and at breakfast, as he was cutting the top off his boiled egg and I was talking about research that was needed, what we needed to discover, what we needed to ask, he looked up and he said, 'Research? I have done all the research that is necessary.' (Interview, 2010)

Sheila Kitzinger's research was directly linked to feminist activism. In 1982, she and her student Janet Balaskas (founder of the Active Birth Movement in the late 1970s), both members of the NCT but not formally representing the organisation, organised the 'Birth Rights Rally', attended by 5000 people on London's Hampstead Heath. Sheila Kitzinger 
recalls this as a career highlight:

At the Royal Free [Hospital] it was decided by the obstetricians that women had to give birth lying down, until and unless it was proved to be safe to do otherwise... Harry Gordon, who was the Reader in Obstetrics at that time, had been allowing women to give birth in any position they chose, and he was ejected, so we wanted to support him.... I think it was 5000 people... All kinds of people in the march, Catholic mothers of eight and lesbian mothers and that was very moving. (Interview, 2010)

This form of activism constituted a direct challenge to obstetric authority, often supporting 'radical' clinicians against prevailing medical norms. In 1985, for example, the NCT and related organisations campaigned in support of obstetrician Wendy Savage who had been professionally suspended for carrying out Caesarean sections 'too late' in labour. While the NCT and other birth organisations saw her low section rate of $6 \%$ as indicating willingness to allow women to labour without intervention, the medical profession regarded it as malpractice. Jenny Kitzinger (1990: 111) notes that there was serious disagreement within the NCT about framing their support of Savage, including lengthy debate about whether they should describe obstetrics as 'male dominated' in their press release. Ultimately they did not include this phrase.

To consolidate and disseminate alternative views of birth, NCT members organised largescale events, making links with midwives who they believed would be more likely to respond to the voices of women articulated in their research and protests. In 1987, for example, Sheila Kitzinger, Balaskas and Beverley Beech of AIMS collaborated with 
independent midwife Melody Weig to host the International Home Birth Conference, attracting 2000 participants from 17 countries. Around this time, NCT president Eileen Hutton initiated formal links with the Royal College of Midwives to create a forum in which antenatal teachers and other NCT members could feed women's experiences in to inform midwifery practice. A similar link was established with the Health Visitors Association a few years later. Describing this work, Hutton said:

We had always been asked to talk to these organisations about what we did: but now, they were inviting us to talk to them about what they did. They were asking us for input from ordinary women about how effectively they were doing their jobs. (quoted in Moorhead, 1996:81)

The NCT came to excel at feeding the experiences garnered by the organisation into policy development and practice. In 1991, for example, they gave evidence to the Health Select Committee on maternity services (the Winterton Committee) instigated by Labour MP Audrey Wise. The resulting Winterton Report on maternity services (House of Commons Health Committee 1992) became a landmark 'tipping point' for birth politics in the UK, according to Mary Newburn, the NCT's Head of Research (personal communication). Hutton was invited to join the Expert Maternity Group that responded to this report in the Department of Health's Changing Childbirth Report (1993). This document evidences the successes of this activist period: it was the first government report to place women at the centre of childbirth, claiming that information provision and choice would empower women to have better births: 'Women should receive clear, unbiased advice and be able to choose 
where they'd like their baby to be born. Their right to make that choice should be respected' (quoted in Moorhead, 1996: 94).

Drawing on the language of feminism, this report exemplifies a new valuation of women's experience that would not have been possible without the Women's Health Movement and feminist politics. It communicates the ways in which an egalitarian liberal feminism had become incorporated within a newly hybridised understanding of the NCT's organisational cause (the NCT was notably not aligned with Radical Feminist campaigns around contraception, abortion, rape and forced sterilisation [Kitzinger, 1990]). Changing Childbirth's emphasis on choice signals a wider historical shift in feminist health politics towards emphasising individual autonomy and informed consumption rather than oppositional resistance to medicalisation. This shift challenges the NCT to develop a model of 'critical consumerism' and consensual or collaborative politics that both resonates with contemporary orientations towards 'choice' and retains a critical edge (Bhavani \& Newburn, 2010).

\section{Fieldnote excerpt: Entrepreneurship and Marketization - HSMOs as Big Business} In a plenary session near the end of the conference, NCT Chief Executive Belinda Phipps came onto the stage to Jimmy Cliff's 'I Can See Clearly Now' (figure 2). Arguing that the NCT's current vision 'isn't big enough', Phipps framed her speech as a consultation with members. Outlining the NCT's aim to produce 'supported and informed parents', 'supportive infrastructure' and 'positive perceptions', she argued that new parents face a 'dilemma': to be fulfilled as people while also meeting their family's needs. Prescribing a shift in the NCT's direction, Phipps exhorted, "So we are stopping advocacy. Now we are looking for win-win 
solutions.' Linking this to the business side of the organisation, Phipps stated that 'the NCT shop will sell dilemma-solving products' to help parents achieve these goals. Members' response to this talk was comparatively muted.

INSERT FIGURE 2 HERE

Figure 2: NCT Chief Executive Belinda Phipps addresses the audience at the NCT Big Weekend, May 2010, Photograph Imogen Tyler, with permission.

Today pregnancy and childbirth have, in Moorhead's (1996: 91) words, 'finally made it out of the closet as a respectable topic of conversation.' Transformations in the public meaning of birth are in no small part due to the NCT's pioneering work in previous decades: the NCT helped to create a radical shift in the UK policy landscape of childbirth. In early 1999, establishing the Maternity Care Working Party (MCWP) - 'an independent, multi-disciplinary body that works to promote normality in childbirth and campaigns for high quality, effective and evidence-based maternity care' (MCWP, 2007: 1) - provided opportunities for collaborative action. In November that year, the NCT co-organised a national conference with The Royal College of Midwives and The Royal College of Obstetricians and Gynaecologists entitled 'The Rising Caesarean Rate - a public health issue"; focussing a multidisciplinary debate that later (in 2007) was articulated through the MCWP's highly significant Consensus Statement on Normal Birth (MCWP, 2007; Werkmeister et al, 2008). vi In the same year (1999) the NCT appointed a new Chief Executive, Belinda Phipps, who remains in this role. Phipps' term of office is associated with a huge increase in membership 
and a more corporate face to the organisation. Sheila Kitzinger (2003: 204) notes that 'with a professional manager at its helm, the NCT became street wise.'

In interview, a senior NCT member explained the MCWP's significance in providing sustained opportunities for 'talking', describing her sense that the organisation needed to cultivate friendly relations with a wider group of midwives and clinicians:

$[A] t$ the time... [w]e were very much a lone organisation going, 'We're right and you're all wrong'. And [Phipps] said 'You can't change it unless you can talk to them. So we better make friends with them, pretty damn fast.' And so we set up the Maternity Care Working Party, which brought everybody together to talk. Best thing we ever did, because we're now very much friends with the midwives and reasonable friends with the obstetricians. (Interview, 2010)

During our study, the NCT both chaired the MCWP and provided a secretariat to the AllParty Parliamentary Group on Maternity Services (APPGM), established in 2001. To date, the NCT's research network remains active, with a committed group of volunteers and paid staff preparing research overviews, policy briefings, lobbying packs and web resources and, most notably in the case of Mary Newburn, participating in research projects and publishing in leading journals (Newburn, 2009; Wiggins \& Newburn, 2004; Birthplace in England Collaborative Group, 2011). The NCT is also regularly asked to give evidence in parliament: in June 2003, for example, they gave evidence at a Health Select Committee Inquiry into Maternity Services in the House of Commons. The organisation was involved in the development of Labour government's National Service Frameworks for Children (in England 
and Wales) and the Clinical Standards for Maternity Services in Scotland and at the time of our study were lobbying for full implementation to ensure access and individualised services are available for all in the UK. At the NCT Big Weekend, talks and workshops focussed on efforts to obtain contracts to deliver services in local children's centres, such as the 'Sure Start' government-sponsored children's centres focussing on supporting families in socially deprived contexts.

Since the late 1990s, the NCT has shifted from being a health advocacy organisation that lobbied government to becoming a powerful political institution in its own right. This shift mirrors a wider shift in UK governance emphasising the role of third-sector organisations in healthcare provision. The NCT's reconfiguration as a powerful third-sector actor blurs the clarity of its original goal to promote and facilitate 'childbirth without fear'. Asked what they considered the cause of the NCT to be, 'ordinary members' who had been involved in the organisation for decades provided the following responses:

I can't remember what our motto is now - it's that every woman should have an experience of birth that enriches her life, or something like that, so it's around supporting all parents, really, so we don't - it's not just what our members want, it's actually we're thinking about all parents. (Interview 2009)

The main raison d'être would be to enable parents to have the best possible experience of birth and becoming parents. And I know that's probably the mission statement or something similar, but it is about just helping, enabling people through this pregnancy, birth and becoming a parent. (Interview 2010) 
As is evident in these descriptions, and in Phipps' Big Weekend 'consultation', the NCT today focuses on parenting rather than 'only' pregnancy, birth and breastfeeding. This new orientation chimed with the Coalition government's emphasis on the delivery of parenting skills as a solution to economic and social problems. As Tracey Jensen (2010: 1) argues, 'the "officialising" of a cultural renewal of parenting has political roots in the New Right' in which the future of the nation is imagined as located 'within private families rather than communities.' Training 'good parents' is envisaged as a means through which the economic costs of delivering social welfare, including health care provision, might be radically reduced in a transfer of responsibility from state to parent-citizens. In positioning itself to deliver parent training, then, the NCT joins what Jensen $(2010: 1,4)$ describes as a 'growing cacophony' of 'self-appointed experts' in the new 'field of parenting expertise'. For the $\mathrm{NCT}$, this work builds on their success in delivering antenatal classes and to pregnant women and their partners, and in developing university validated courses for NCT antenatal teachers and breastfeeding counsellors.

This shift has also been accompanied by a move into commercial activities and closer relationships with corporations: the Big Weekend was 'proudly sponsored by Pampers' (a disposable nappy brand owned by the multi-national Proctor \& Gamble) and involved workshops on how to garner such sponsorship. The glossy NCT magazine sent out to members is full of advertisements promoting expensive family-friendly holidays, fashion and other consumer items. The NCT no longer wants to appear 'natural' or domestic: one member was told by ' $\mathrm{HQ}$ ' that conference badges she had hand-made for her branch members were 'not corporate enough' this year (fieldnotes). In interviews some NCT actors displayed ambivalence about these changes, but on the whole remained optimistic and 
positive about the political and social effects of their work. One senior member noted that the new approach 'has been very successful in growing the charity in terms of size and income... [and that] you can't achieve what we want to achieve unless we have the infrastructure to do that.' She argued:

A real strength of the NCT is that we have this big extensive network providing support networks for parents. Out of those we get in new people who want to train as specialist workers, we deliver services to parents, which are essentially parent centred... We encourage people to both read research and get involved... in research groups and also to be active locally on [maternity services liaison] committees.... [I]t's a lovely model, it could all be done better, more comprehensively, more systematically, bigger numbers, more accessible, but nevertheless it's an extraordinary achievement (interview, February 2010).

Potential tensions between obtaining corporate sponsorship, selling products and facilitating local activism are overlooked here: instead, the benefits of organisational growth - for example, the potential to pay research staff or to reach more parents - are highlighted.

\section{Achievements and influence}

As a HSMO, the NCT is arguably a stunning success: in just over 50 years it has achieved a central place in British policy-making on birth, developed a large membership and achieved a comfortable financial position. Whilst the NCT's success in the policy arena is outstanding, there has been endemic governmental failure to implement the Changing Childbirth 
Report's recommendations. Women giving birth in England are still faced with high rates of Caesarean section and epidural use, and struggle in most places to have a choice about birth location (Dodwell \& Newburn, 2010). This remains an area of continued work within the NCT: Newburn, for example, is a co-investigator in the 'Birthplace in England National Prospective Cohort Study' (Brocklehurst et al, 2011).

In the UK, opportunities for health social movements to influence public policy have increased over recent decades (Allsop et al 2004, Alvarez-Rosete \& Mays 2008, Landzelius 2006a). There has been a shift, variously conceptualised, from a top-down, centralised mode of governance to one with seemingly more opportunity for participation. However, as our study reveals, this shift is far from complete: outcomes are disputed and the power relations between state, medicine and patient groups remain contested. ${ }^{\text {vii }}$ Critics argue this policy orientation forms part of a neoliberal governmental agenda through which welfare programmes are dismantled as profit-driven and charitable HMSOs replace state-funded health care provision. Allsop et al (2005: 753) ask whether 'health consumer groups could simply become actors in a process that provides enhanced legitimacy to governments as they pursue their own larger agenda' (see also Baggott, Allsop \& Jones, 2005: 292-297; Landzelius 2006a). Our analysis of the NCT suggests that influence in policy-making may sideline the organisation's more oppositional political dimensions.

In 1990 Jenny Kitzinger (1990: 113) presciently argued that 'The NCT did vital political groundwork, by setting up as a lay movement in the first place and fighting to reconstruct the meaning of birth. [....] The danger is ... that the NCT could be becoming institutionalized and professionalized [....] preventing its growth in any very challenging direction.' For her, 
the NCT's power lay in its identity as a lay movement; despite the seemingly incompatible ideological strands within the organisation, its independence from medicine and government gave it a particular kind of authority and power. Our study shows that this shift from a lay movement to a professionalised organisation is well under way. Interviewees noted this shift, referring to the organisation's increased reliance on paid staff, the centralised management of ante-natal classes, the decline in direct involvement of local branches in teacher training and the validation of NCT antenatal training by the University of Worcester, as well as the increased membership and successful commercial activities.

Analysing the NCT's shifting cause regimes exemplifies how HSMOs, often emerging from marginal and/or oppositional contexts, risk losing their purchase as they are reconfigured in a professionalised health activist landscape (Katz, 2006: 65). The current era of 'thirdification' commissioning and a co-current professionalization of activism impact organisations' ability to campaign against government policies: HSMOs risk muting their contestational voices in expanding their organisational influence by working more closely with the state. Yet the NCT's history also reveals a multiplicity of cause regimes: an organisation created for upper-class women is reshaped by liberal feminism and middleclass aspirations before being partially co-opted by neoliberal imperatives. Whilst our case study tracks the ascendance of consumerism and individualism in health politics that stultify the possibility of autonomous and collective action, it also emphasises the persistence of folded cause-regimes.

\section{Conclusion: Hybrid Cause Regimes}


Our research asked: for what is the NCT fighting? What kind of fight is this? And on whose behalf is it being fought? The increasingly hybrid cause regime of the NCT makes these questions quite difficult to answer. Indeed, the very framing of organisational cause as 'fight' sits uncomfortably with the NCT's contemporary orientation towards influencing policy-making, service-provision and brand consolidation. As Phipps declared, parts of the NCT no longer understand it as an organisation 'fighting for change' or even as an advocacy organisation: 'Now we are looking for win-win solutions.' Yet, our analysis reveals that the cause regimes dominant in each phase of the NCT's history are folded into each other in complex and sometimes contradictory ways; they do not disappear.

The work of some NCT members reveals the persistence of more activist practices within the organisation, creating support networks for socially marginalized and vulnerable women, for example. In Leeds we met an NCT teacher providing free antenatal classes to asylum-seeking women and newly arrived migrants, not only preparing women for childbirth but assisting with housing, food and clothing as well as mental health support. Indeed, all the NCT members we spoke to emphasised the social significance of supporting and educating pregnant women before and after birth and many remained convinced of the importance of advocating for social change around birth, motherhood and breastfeeding. Activism, care and advocacy persist in the organisation in the face of its neoliberalisation, revealing the folding of multiple cause regimes and the positive material consequences of a complex organisational history.

The NCT's longevity is drawn upon by its leaders as a source of coherence and strength. At the same time, the multiple and complex cause regimes in play within this organisation 
mean that this history is also a source of tension and contradiction. Our EPOKS colleagues found similar tensions within AD organisations. Our findings and the EPOKS project more broadly highlight key questions for sociological analysis of contemporary health activism. We argue that hybridity of cause can be a potential strength as well as a weakness for HSMOs. The co-existence of diverse and conflicting ideologies can help ensure an organisation's broad appeal amid the emergence of potentially competing organisations. At the same time, as some HSMOs become akin to corporations, the possibility of reanimating oppositional activism diminishes. As advocacy is recast as 'opportunity', sociologists and activists alike must ask at what point the hybridisation of cause regimes and related domain expansion transform HSMOs into de-fanged market-driven organisational formations, diminishing their ability to effect change. Despite this, we have argued here that the NCT's folded cause regimes also provide reasons for hope; allowing for a large membership to identify with the organisation and to participate in a wider variety of activities.

UK birth politics remain fraught, with some desired changes seemingly very difficult to achieve (choice of place of birth being one key example). It is too early to say whether the NCT's latest cause regime - its turn towards a corporatised third sector model - will debilitate the organisation's capacity to improve the experience of birth and parenting. Our study's uncovering of confusion and conflict around this new cause regime and the persistence of other distinct pockets of cause-related practices highlights both tensions and opportunities for continuing struggle for more humane and just forms of childbirth.

\section{References}


Akrich M (2010) From communities of practice to epistemic communities: health mobilizations on the internet. Sociological Research Online 15(2) www.socresonline.org.uk/15/2/10.html

Allsop J, Jones K and Baggott R (2004) Health consumer groups in the UK: a new social movement? Sociology of Health and Illness 26(6): 737-756.

Alvarez-Rosete A and Mays N (2008) Reconciling two conflicting tales of the English health policy process since 1997. British Politics 3: 183-203.

Baggot R, Allsop J and Jones K (2005) Speaking for Patients and Carers: Health Consumer Groups and the Policy Process. Palgrave Macmillan: Houndsmills and New York. Baggott R and Forster R (2008) Health consumer and patients' organizations in Europe: towards a comparative analysis. Health Expectations 11: 85-94.

Birthplace in England Collaborative Group (2011) Perinatal and maternal outcomes by planned place of birth for healthy women with low risk pregnancies: the Birthplace in England national prospective cohort study. British Medical Journal (343):d7400

Brown P and Zavestoski S (2004) Social movements in health: an introduction. Sociology of Health and IIIness 26(6): 679-694.

Brown P, Zavestoski S, McCormick S, Mayer B, Morello-Frosch R and Altman RG (2004) Embodied health movements: new approaches to social movements in health. Sociology of Health and IIIness 26(6): 50-80.

Caton D (1996) Who said childbirth is natural? The medical mission of Grantly Dick-Read. Anesthesiology 84(4): 955-964.

Crossley N (2006) The field of psychiatric contention in the UK, 1960-2000. Social Science and Medicine 62: 552-563. 
Davis A (2012) Modern Motherhood: Women and Family in England c. 1945-2000.

Manchester: Manchester University Press.

Department of Health (1970) The Peel Report. London: HMSO.

Department of Health (1993) Changing Childbirth: The Report of the Expert Maternity Group. London: HMSO.

Dick-Read G (1933) Natural Childbirth. London: Heinemann.

Dick-Read G (1942) Childbirth Without Fear. New York: Harper.

Dick-Read G (Director) (1956) Childbirth Without Fear.

Dodwell M and Newburn M (2010) Normal Birth as a Measure of the Quality of Care:

Evidence on Safety, Effectiveness and Women's Experiences. London: NCT.

Epstein S (2007) Patient groups and health movements. In Hackett EJ, Amsterdamska O, Lynch M, Wajcman J (eds) The Handbook of Science and Technology Studies, 3rd Edition. Cambridge: MIT Press, 499-540.

Fotaki M (2010) Patient choice and equity in the British National Health Service: towards developing an alternative framework. Sociology of Health and IIIness 32(6): 898-913. Hess DJ (2004) Medical modernisation, scientific research fields and the epistemic politics of health social movements. Sociology of Health and Illness 26(6): 695-709.

House of Commons Health Committee (1992) Second Report on the Maternity Services (Winterton Report). London: HMSO.

HM Government (2011) Government launches Big Society programme, Number 10 Downing Street, 18 May. www.number10.gov.uk/news/big-society/ (Accessed 26.4.12). Jensen T (2010) Warmth and wealth: re-imagining social class in taxonomies of good parenting. Studies in the Maternal 2(1): 1-13. 
Johanson R, Newburn M and Macfarlane A (2002) Has the medicalization of childbirth gone too far? British Medical Journal 324(7342): 892-895.

Johnston, H \& Noakes, JA (eds) (2005) Frames of Protest: Social Movements and the Framing Perspective, Oxford: Rowman and Littlefield

Jones K (2008) In whose Interest? Relationships between health consumer groups and the pharmaceutical industry in the UK. Sociology of Health and IIIness 30(6): 929-943.

Katz C (2005) Partners in Crime? Neoliberalism and the production of new political subjectivities, Antipode 37(3): 623-631.

Kitzinger J (1990) Strategies of the early childbirth movement: a case study of the NCT. In Garcia J, Fitzpatrick R, Richards M (eds) The Politics of Maternity Care: services for childbearing women in twentieth century Britain. Oxford: Oxford University Press. Kitzinger S (1975) Some Mothers' Experiences of Induced Labour. Submission to the Department of Health and Social Security from the National Childbirth Trust. Kitzinger S (2003) Sheila Kitzinger's letter from Europe: The politics of birth. Birth 30(3): 203205.

Klawiter M (2004) Breast cancer in two regimes: the impact of social movements on illness experience. Sociology of Health and IIIness 26(6): 845-874

Klawiter M (2006) The Biopolitics of Breast Cancer: Changing cultures of disease and activism. Minnesota University Press: Minneapolis.

Landzelius K (2006a) Introduction: patient organization movements and new metamorphoses in patienthood. Social Science and Medicine 62: 529-537. Landzelius K (2006b) The incubation of a social movement? Preterm babies, parent activists, and neonatal productions in the US context. Social Science and Medicine 62: 668-682. 
Layne L (2006) Pregnancy and infant loss support: a new, feminist, American, patient movement? Social Science and Medicine 62: 602-613.

Martin GP (2008) 'Ordinary people only': knowledge, representativeness and the publics of public participation in healthcare. Sociology of Health and IIIness 30(1): 35-54.

Maternity Care Working Party (2007) Making Normal Birth a Reality: Consensus statement from the Maternity Care Working Party. www.mcwp.org.uk

Milewa T, Valentine J and Calnan M (1999) Community participation and citizenship in British health care planning: narratives of power and involvement in the changing welfare state. Sociology of Health and IIIness 21(4): 445-465.

Moorhead J (1996) New Generations: 40 years of Birth in Britain (National Childbirth Trust Guides. London: Stationary Office Books.

Moscucci O (2003) Holistic obstetrics: the origins of 'natural childbirth' in Britain. Postgraduate Medical Journal 79: 168-173.

National Childbirth Trust Leeds Branch (2007) The Rattle. Autumn 07. Available at: http://www.nctleeds.org/resources/rattle autumn07.pdf

Newburn M (2009) Promoting and protecting normal birth. The Practising Midwife 12(6): 46.

O'Donovan O, Moreira T and Howlett E (2013) Tracking transformations in health movement organisations: Alzheimer's Disease organisations and their changing cause regimes. Social Movement Studies: Journal of Social, Cultural and Political Protest. 2(3): 1-17.

Rabeharisoa V, Moreira T and Akrich M (eds) (2014) Special Issue: Evidence-based activism: Patients', users' and activists' groups in knowledge society. BioSocieties 9(2)

Thomas M (ed.) (1997) Post-War Mothers: Childbirth Letters to Grantly Dick-Read, 19461956. Woodbridge, Suffolk: University of Rochester Press. 
Trickey H and Newburn M (2012) Goals, dilemmas and assumptions in infant feeding education and support: applying theory of constraints thinking tools to develop new priorities for action. Maternal and Child Nutrition June 19. http://onlinelibrary.wiley.com/doi/10.1111/j.1740-8709.2012.00417.x/pdf

Tyler S (2002) Comparing the campaigning profile of maternity user groups in Europe: can we learn anything useful? Health Expectations 5(2): 136-147.

Tyler I, Gill N, Conlon D, Oeppen C (2014) The business of child detention: charitable cooption, migrant advocacy and activist outrage. Race \& Class 56(1): 3-21.

Werkmeister G, Jokinen M, Mahmood T and Newburn M (2008) Making normal labour and birth a reality: developing a multi-disciplinary consensus. Midwifery 24(3): 256-259.

Wiggins M and Newburn M. (2004) Information used by pregnant women and their understanding and use of evidence-based "informed choice" leaflets. In Kirkham M (ed.) Informed Choice in Maternity Care. London: Palgrave Macmillan, 147-168 


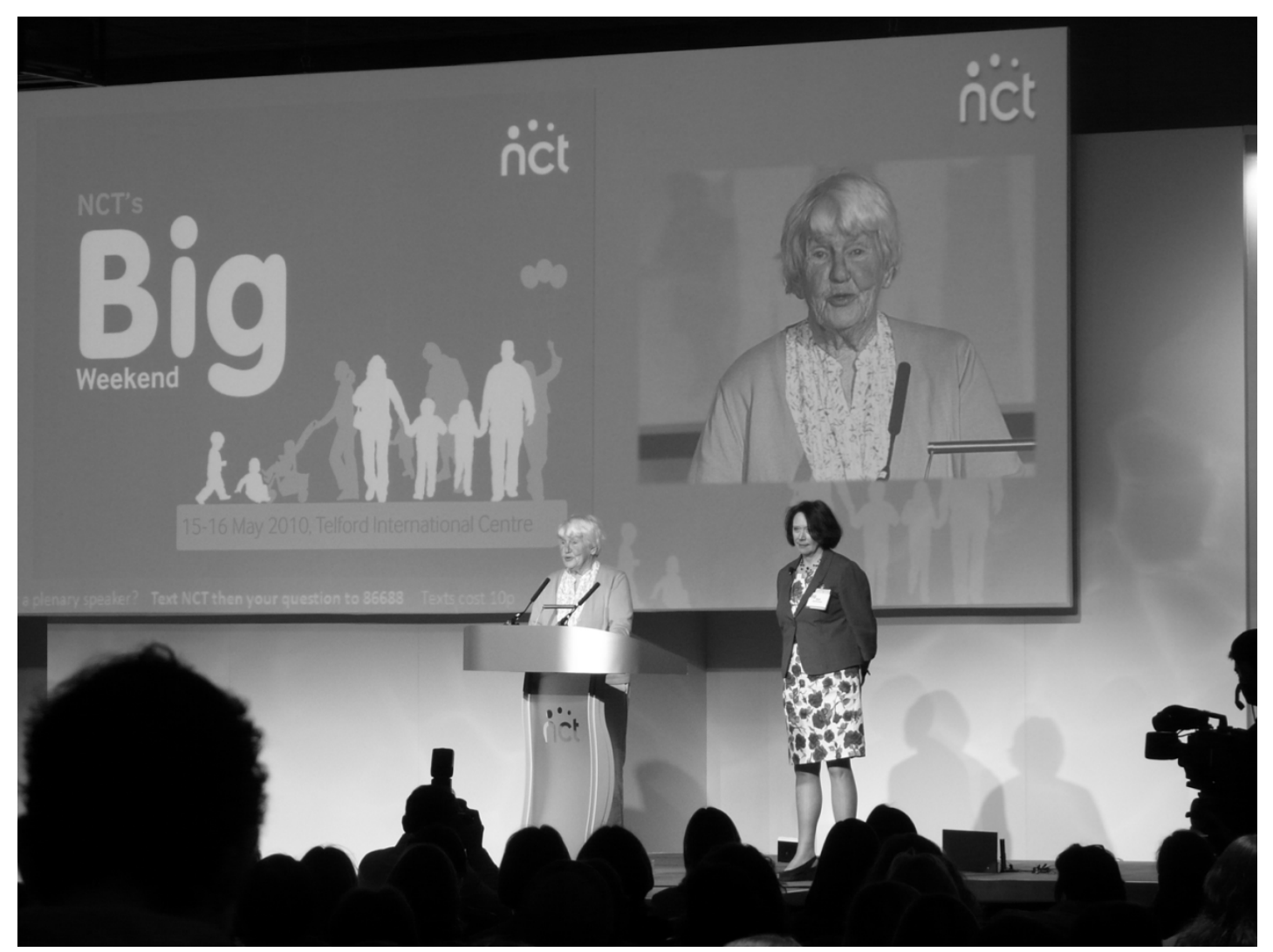

Figure 1 


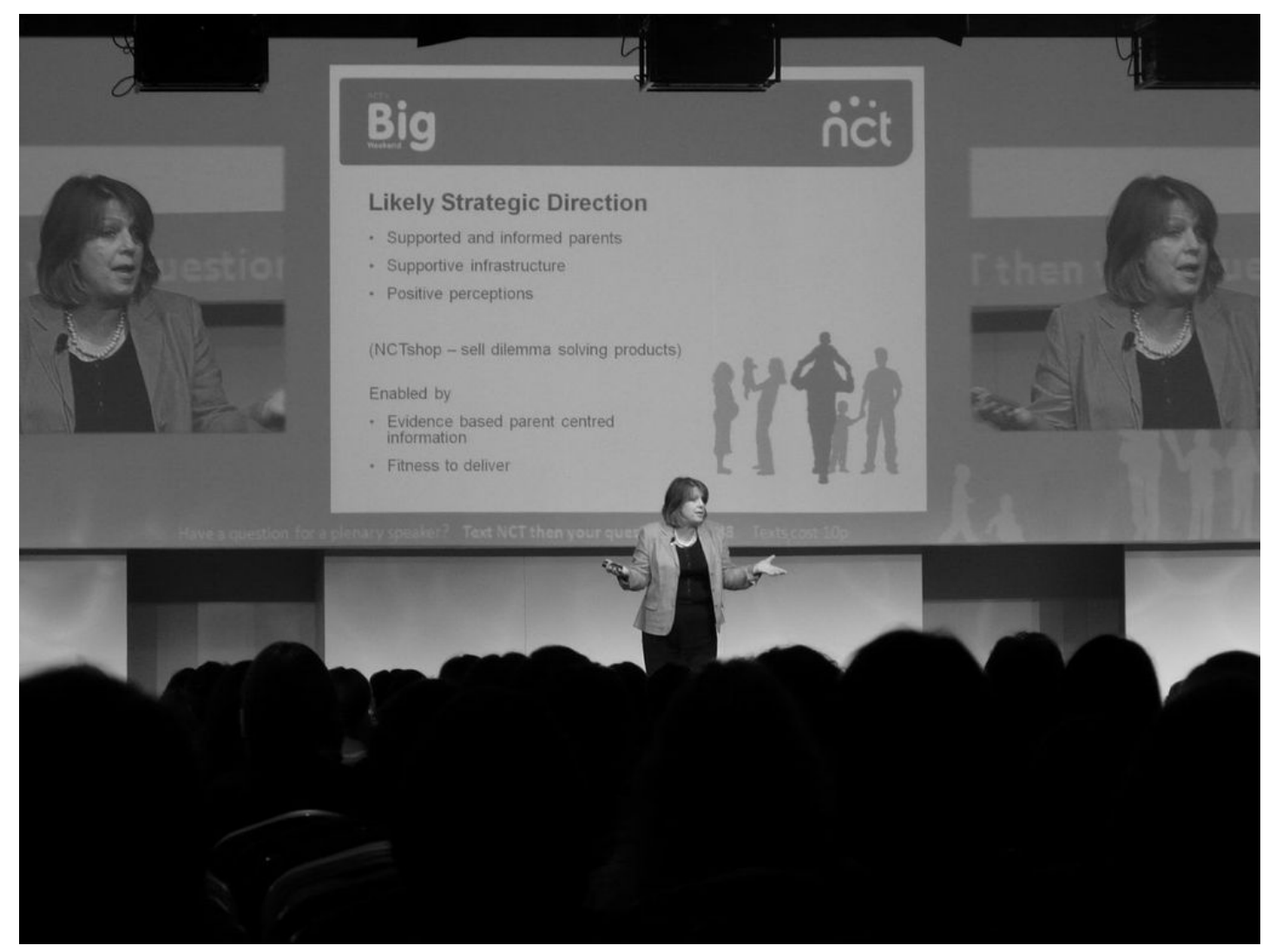

Figure 2

\begin{abstract}
i Some existing scholarship describes various phases or generations of activism: Linda Layne's (2006) research on the US pregnancy and infant loss support movement describes two developmental phases, each characterised by different relations between patient organisations, the women's movement and physicians; Klawiter (2004) makes a similar argument about American breast cancer activisms, exploring the impact of activism on one woman's experience of cancer (see also Klawiter, 2006).

ii Originally named the Natural Childbirth Association, the organisation was quickly renamed the National Childbirth Trust. Today it is known simply as the 'NCT'. These two shifts succinctly encapsulate the changes in orientation of the organisation as described in this paper.

iii All interviews were conducted by Author 3, recorded and transcribed verbatim. We have only used interviewees' names when they have explicitly granted permission; other interviewees remain anonymous. Detailed fieldnotes were taken immediately after all observations and discussed with the research team.
\end{abstract}

iv We are grateful to NCT members for detailed comments on our work and note that our analysis does not always accord with members' views. For detailed information about EPOKS see www.csi.ensmp.fr/WebCSI/EPOKSWebSite/ and papers in Rabeharisoa, Moreira and Akrich (2014).

${ }^{v}$ See www.nct.org.uk/about-nct/our-history.

vii For examples in other fields of activism, see Alvarez-Rosete and Mays 2008, Fotaki 2010, Jones 2008, Hess 2004, Martin 2008, Milewa et al 1999, Baggott and Forster 2008; Baggott, Allsop and Jones, 2005. 